HEMPE \& NOGUERA, v(5), n5, p. 682 - 695, 2012.

Revista Eletrônica em Gestão, Educação e Tecnologia Ambiental

REGET/UFSM (e-ISSN: 2236-1170)

\title{
A EDUCAÇÃO AMBIENTAL E OS RESIDUOS SÓLIDOS URBANOS ${ }^{1}$
}

\author{
Cléa Hempe ${ }^{2}$, Jorge Orlando Cuellar Noguera ${ }^{3}$ \\ ${ }^{1}$ Artigo apresentada no II Congresso Internacional de Educação Ambiental Curso de Especialização em Educação \\ Ambiental UFSM - Polo UAB Panambi/RS VI Seminário Municipal do Meio Ambiente. \\ ${ }^{1}$ Graduada em Geografia pela UNIJUI, Especialista em Gestão e Apoio Pedagógico na Educação Básica \\ (UNICRUZ), Especialista em Mídias na Educação (UFSM),Tutora do Curso de Educação Ambiental/Polo Presencial de \\ Panambi-RS e Mestranda em Geografia (UFSM). \\ ${ }^{1}$ Co-autor, coordenador do Curso de Especialização em Educação Ambiental. UFSM.
}

\section{RESUMO}

O objetivo geral da oficina consistiu em proporcionar o conhecimento em relação à história do surgimento dos resíduos, as formas de disposição de recolhimento no Brasil, conceitos de resíduos sólidos, três "R,s" e a legislação. A metodologia consistiu em três etapas: explanação oral, uso de vídeos e por último sugestões de jogos interativos de educação ambiental. O conceito de resíduo e lixo pode variar conforme a época e o lugar. Dependem de fatores jurídicos, econômicos, ambientais, sociais e tecnológicos, como afirma Calderoni (1998). A definição e a conceituação do termo resíduo e lixo tem diferido conforme a situação em que seja aplicada. Conforme Yoshitake (2010) lixo é todo e qualquer material descartado pela atividade humana, doméstica, social e industrial, que é jogado fora, pois para o seu proprietário não tem mais valor. Este desperdício pode ocorrer por problemas ligados à recicláveis, entre outras razões. A oficina teve o intuito de conscientizar e sensibilizar sobre a importância da separação dos resíduos sólidos e a utilização dos três "R,s". Os alunos participaram da oficina jogando, isto é, separando virtualmente os materiais de forma correta.

Palavras - chaves: Resíduos Sólidos. Práticas. Ensino.

\section{INTRODUÇÃO}

No início da aventura humana sobre a terra, cavernas eram habitadas por homens, caçadores e pescadores, cujo corpo, para ser protegido do frio, era coberto por peles de animais. Esta pequena população era formada por nômades. Quando numa determinada região habitada, a comida escasseava, as tribos errantes se mudavam para outra região e os seus "lixos", eram deixados sobre o meio ambiente, logo decompostos pela ação do tempo (NOGUERA, 2010).

$\mathrm{Na}$ medida em que o tempo foi passando e o homem foi "civilizando-se", este iniciou a fabricação de peças de cerâmicas. Estas foram produzidas para promover maior conforto, pode-se destacar: vasilhames de cerâmica, instrumentos para o plantio, roupas mais apropriadas. Hábitos 
HEMPE \& NOGUERA, v(5), n5, p. 682 - 695, 2012.

Revista Eletrônica em Gestão, Educação e Tecnologia Ambiental

REGET/UFSM (e-ISSN: 2236-1170)

como construção de moradias, criação de animais, cultivo de alimentos, fixação permanente em um local foram desenvolvidos, também. A produção de lixo foi aumentada, mas ainda não havia se constituído em um problema mundial. O desenvolvimento torna-se acentuado ano a ano e a população humana, consequentemente, tem aumentado.

O objetivo geral da "oficina de reciclagem" realizada no II Congresso Internacional de Educação Ambiental e VI Seminário Municipal do Meio Ambiente consistiu em proporcionar aos discentes da educação básica e demais interessados o conhecimento em relação à história do surgimento dos resíduos, as formas de disposição de recolhimento no Brasil e em Panambi-RS, os conceitos de resíduos sólidos, os três "R,s" e informar sobre a legislação estadual, nacional e municipal dos resíduos sólidos.

A oficina de reciclagem foi apresentada a convite de membros da comissão organizadora do evento, uma vez que faz parte do tema de mestrado em Geografia-UFSM. E como pesquisadora tenho o dever de colaborar socializando os saberes adquiridos até o presente momento do já li e escrevi sobre o tema.

Existem várias autores que já vem realizando pesquisas sobre a problemática dos resíduos sólidos, entre eles destaca-se: Amorim (2010); Baratto (2010), Guanabara (2008); Felix (2007); Flick (2010); Freire (2009); Fernandes (2008); Hempe (2010), Córdula (2009); Leite (2004); Melo (2009); Brito (S.D); Yoshitake (2010); Ramos (2010), Noguera (2010), Lima (2010), Scheren (2004); entre outros.

Os autores nomeados tem tido como objeto de estudo: os diferentes conceitos de resíduos sólidos e lixo, as legislações estaduais e federais, as formas de disposição adotadas para os resíduos sólidos urbanos, a coleta seletiva, reciclagem e a reutilização, o uso de jogos para ensino de educação ambiental, o uso das tecnologias nas práticas ambientais, entre outros temas.

Este artigo está dividido em quatro capítulos. No primeiro apresenta-se a introdução, à temática, o objetivo e a justificativa da pesquisa. O capítulo dois traz o referencial teórico e tem como título: "Problemas Ambientais: contextualizações". O referencial traz a visão dos autores mencionados no parágrafo anterior sobre resíduos sólidos, conceitos e diferença entre resíduo e lixo, classificação dos resíduos, legislação, formas de disposição adotadas no Brasil e a importância do papel do professor quanto ao uso das tecnologias para utilizar para trabalhar a educação ambiental. O capítulo três apresenta a sistematização e a análise dos resultados da oficina de reciclagem oportunizada aos alunos da educação básica do município de Panambi- RS, no II Congresso Internacional de Educação Ambiental e VI Seminário Municipal do Meio ambiente - realizado pela Universidade Federal de Santa Maria, Curso de Especialização em Educação Ambiental, Centro de Tecnologia - UFSM, Polo de Apoio Presencial de Panambi-RS, Conselho Municipal do Meio Ambiente e Associação dos Engenheiros Agrônomos de Panambi, Santa Bárbara do Sul e Condor-AEAPSC e Prefeitura Municipal de Panambi. E por último apresenta-se a Conclusão e as Referências.

\section{PROBLEMAS AMBIENTAIS: CONTEXTUALIZAÇÕES}

A partir da segunda metade do século XX foi iniciada uma reviravolta e a humanidade torna-se preocupada com o planeta onde vive. Outras inquietações como o buraco na camada de ozônio, o aquecimento global da Terra tem despertado a população mundial sobre o que tinha acontecido com o meio ambiente. Nesse "despertar", a questão da geração e destinação final do lixo foi percebida, e nesta primeira década do século XXI tem sido enfrentada com a urgência necessária (UFMG, 2010 apud NOGUERA, 2010). 
HEMPE \& NOGUERA, v(5), n5, p. 682 - 695, 2012.

Revista Eletrônica em Gestão, Educação e Tecnologia Ambiental

REGET/UFSM (e-ISSN: 2236-1170)

\author{
O lixo tem apresentado seu lado trágico,
}

\begin{abstract}
pois é um indicador curioso de desenvolvimento de uma nação. Quanto mais pujante for a economia, mais sujeira o país irá produzir. Ë o sinal de que o país está crescendo, de que as pessoas estão consumindo mais. O problema está ganhando uma dimensão perigosa por causa da mudança no perfil do lixo. Na metade do século XIX, a composição do lixo era predominantemente de matéria orgânica, de restos de comida. Com o avanço da tecnologia, materiais como plásticos, isopores, pilhas, baterias de celular e lâmpadas são presença cada vez mais constante na coleta (REVISTA VEJA, 1999 apud NOGUERA, 2010, p.5).
\end{abstract}

Os resíduos sólidos urbanos são resultado do crescimento populacional e do consumo. 0 consumo é dependente da época, das atividades econômicas e culturais. Segundo Noguera (2010), duas épocas devem ser observadas, a primeira época surgida com o aparecimento do homem até a Revolução Agropastoril onde a grande quantidade de resíduos produzidos, era de origem alimentar. A segunda época dos resíduos sólidos, segundo Moura (2006) e Noguera (2010) foi iniciada com a Revolução Industrial. Esta fase é caracterizada pela mudança de produção, da forma artesanal a industrial, trazendo uma série de mudanças de comportamento. Noguera (2010) exemplifica ao afirmar que o consumo aumenta com a os problemas de poluição. Com a Revolução Industrial, no século XIX ocorreu o acúmulo de capital e os recursos demandam e por esta razão a produção de resíduos também aumenta cuja causa tem sido naturais passaram a ser explorados e retirados da natureza de forma ilimitada o que tem trazido grande desequilíbrio na biodiversidade do planeta. O contexto vivido com a Revolução Industrial desencadeou a necessidade de produzir em grandes quantidades e com maior rapidez. A Inglaterra chegou à frente com o desenvolvimento de máquinas a vapor.

As inovações introduzidas na indústria têxtil deram à Inglaterra vantagem no comércio mundial dos tecidos de algodão, a partir de 1780. O tecido era barato e podia ser comprado por milhões de pessoas que jamais haviam desfrutado o conforto de usar roupas leves e de qualidade. Segundo alguns historiadores, a combinação das invenções no campo da indústria têxtil e a máquina a vapor, principalmente na indústria de mineração, dos transportes ferroviários e marítimo, que, num período de 100 anos (1770 a 1870), tem caracterizado e promovido a grande Revolução Industrial. A partir daí tem ocorrido um enorme aumento da produtividade, em função da utilização dos equipamentos mecânicos, da energia a vapor e, posteriormente, da eletricidade, que tem passado a substituir a força animal e, ainda mais agravante, dispensa o trabalho humano. Esse aumento de produtividade aliado ao excesso de mão-de-obra tem gerado, inevitavelmente, desemprego. Os mais abastados tem passado a consumir mais e o consequentemente a produção de resíduos tem se acumulado.

A Revolução Industrial tornou os métodos de produção mais eficientes. Os produtos passaram a ser produzidos mais rapidamente e, baratos tem estimulado o consumo. Por outro lado, tem aumentado o número de desempregados. A máquina tem substituído, aos poucos, a mão-de-obra humana. As conseqüências foram muitas, dá-se destaque a poluição ambiental, o êxodo rural e o crescimento desordenado das cidades muito nocivas para a sociedade, surgindo à problemática da poluição ambiental.

A poluição ambiental pode ser definida como a ação de contaminar as águas, solos e ar. Tem ocorrido com a liberação no meio ambiente de lixo orgânico, industrial, gases poluentes, objetos materiais, elementos químicos, entre outros, o que tem prejudicado o funcionamento dos ecossistemas, até matado várias espécies animais e vegetais. O homem também é prejudicado 
HEMPE \& NOGUERA, v(5), n5, p. 682 - 695, 2012.

com este tipo de ação, pois depende muito dos recursos hídricos, do ar e do solo para sobreviver com qualidade de vida e saúde. Os principais poluentes ambientais são: chumbo, mercúrio, benzeno, enxofre, monóxido de carbono, pesticidas, dioxinas e gás carbônico.

A saída da população do campo tem provocado, na maioria das vezes, problemas sociais, tais como: empregos insuficientes e grande parte dos migrantes ingressando no mercado de trabalho informal e passado a residir em habitações precárias favelas, cortiços, etc. Além das pessoas não conseguirem emprego, o êxodo rural descontrolado causa outros problemas nas grandes cidades, aumenta em grandes proporções a população nos bairros de periferia. Como são bairros carentes em hospitais e escolas, a população destes locais tem sobrevivido a grandes sofrimentos em relação ao atendimento destes serviços, ou seja, escolas com excesso de alunos por sala de aula e hospitais superlotados tem sido algumas as conseqüências. Com o aumento do número de habitantes residindo na zona urbana aumenta a produção de resíduos sólidos.

\subsection{Os resíduos sólidos na visão de alguns autores}

Para Amorim (2010), a produção de resíduos está ligada diretamente ao modo de vida, cultura, trabalho, ao modo de alimentação, higiene e consumo humanos. Destaca em seus estudos o desenvolvimento de tecnologias e a produção de materiais artificiais, porém a preocupação com a reintegração desses materiais ao meio ambiente não tem sido alvo de preocupação pelas indústrias que a produzem.

Enquanto que Layrargues (2002) apud (GUANABARA, 2008, p.126) reforça a ideia destacada por Amorim ao afirmar que para cada tonelada de lixo gerada pelo consumo, vinte são geradas pela extração dos recursos e cinco durante o processo de industrialização. $O$ fato é que consome-se mais do que é realmente preciso, e assim, o desperdício que vem junto ao excesso de consumo, também tem contribuído com o aumento dos resíduos que são gerados.

Ainda coloca que muitos aparelhos são lançados ao lixo por apresentarem algum defeito, pois não vale à pena serem consertados, uma vez que o conserto pode ser maior do que adquirir outro aparelho novo. De acordo com Layrargues (2002) a obsolescência planejada tem acontecido quando as pessoas são obrigadas a consumir bens que se tornam obsoletas antes do tempo. A tecnologia tem evoluído a cada dia com mais rapidez e o consumidor não tem conseguido acompanhar a aquisição de equipamentos e/ou a realização de trocas com a mesma rapidez.

Segundo Scheren (2004) estudos realizados pelo IBGE (2000) têm indicado que uma média de $75 \%$ de todo o lixo gerado no Brasil tem destino os dejetos a céu aberto, conhecidos por lixões. Do ponto de vista sanitário esta tem sido uma prática condenável, pois causa vários problemas ao meio ambiente e a saúde das populações. Os resíduos sólidos urbanos gerados nas cidades tem sido motivo de preocupação nas últimas décadas, pois tem causado crescente poluição e impactos socioambientais devido à disposição final inadequada. Nos lixões, os principais problemas provocados são a proliferação de vetores de doenças, geração de maus odores, poluição do solo e das águas subterrâneas e superficiais, pela infiltração do lixiviado, resultante dos processos de decomposição dos resíduos Sólidos Urbanos (SISINNO e MOREIRA, 1996; TRESSOLDI e CONSONI, 1998; TAKAYANAQUI, 2005 apud MELO, 2009). 
HEMPE \& NOGUERA, v(5), n5, p. 682 - 695, 2012.

Revista Eletrônica em Gestão, Educação e Tecnologia Ambiental

REGET/UFSM (e-ISSN: 2236-1170)

\subsection{Conceitos: diferença entre resíduos e lixo}

O conceito de lixo e de resíduo pode variar conforme a época e o lugar. Estes conceitos variam dependendo de fatores jurídicos, econômicos, ambientais, sociais e tecnológicos como afirma Calderoni (1998) apud Yoshitake (2010).

A definição e a conceituação do termo resíduo e lixo tem diferido conforme a situação em que seja aplicada. Conforme Yoshitake ( 2010) lixo é todo e qualquer material descartado pela atividade humana, doméstica, social e industrial, que é jogado fora, pois para o seu proprietário não tem mais valor. Já para Amorim (2010) lixo é tudo o que é descartado e que não é percebido e que não possui utilidade imediata.

Yoshitake (2010) tem definido resíduo como sobra no processo produtivo e é equivalente a refugo ou rejeito. Em outras situações, a conceituação de resíduo é equivalente a lixo. "Na opinião de Calderoni (1998), é neste sentido a definição dada ao termo resíduo pela Associação Brasileira de Normas Técnicas (ABNT): material desprovido de utilidade pelo seu possuidor." (sic) (Normas Brasileiras Registradas - NBR 12.980, 1993, item 3.84, p.5) apud Yoshitake (2010).

Para Amorim (2010) o vocábulo lixo pode ser chamado de resíduo, quando é descartado e é reutilizado. Define ainda que a denominação lixo geralmente seja utilizada no vocabulário das escolas.

Calderoni (1997) apud Yoshitake (2010) afirma que sob o ponto de vista econômico, resíduo ou lixo é todo o material que uma dada sociedade ou agrupamento humano desperdiça. Este desperdício pode ocorrer por problemas ligados à disponibilidade de informações, por falta de desenvolvimento de um mercado para produtos recicláveis, entre outras razões.

A Associação Brasileira de Normas Técnicas - ABNT 10004 no item três tem definido os resíduos sólidos e semi-sólidos:

[...] que resultam de atividades da comunidade de origem: industrial, doméstica, hospitalar, comercial, agrícola, de serviços e de varrição. Ficam incluídos nesta definição os lodos provenientes de sistemas de tratamento de água, aqueles gerados em equipamento e 1 . Instalações de controle de poluição, bem como determinados líquidos cujas particularidades tornem inviável o seu lançamento na rede pública de esgotos ou corpos de água que exijam para isso soluções técnicas economicamente inviáveis em face da melhor tecnologia disponível (ABNT, 2004).

Pela definição anterior, os resíduos sólidos são provenientes de diversas fontes geradoras e tem apresentado características diferentes. Uns, mais volumosos, como o entulho da construção civil; outros apodrecem rapidamente, como é o caso de cascas de frutas e restos de alimentos; outros são tóxicos, pilhas e baterias são citadas como exemplo. Conhecer as propriedades e características dos resíduos é de fundamental importância para o bom gerenciamento deles.

Na seção seguinte, é apresentada a caracterização e a classificação dos resíduos sólidos.

\subsection{Resíduos sólidos: classificação dos resíduos e a legislação}

No Brasil, a NBR 10004 (ABNT, 2004) tem apresentado a classificação dos resíduos sólidos conforme os riscos potenciais ao meio ambiente: Os resíduos são classificados em três classes: resíduos classe I perigosos, resíduos classe II não inertes ou banais e resíduos classe III inertes. 0 quadro 1 que segue apresenta a classificação dos resíduos e suas características. 
HEMPE \& NOGUERA, v(5), n5, p. 682 - 695, 2012.

Revista Eletrônica em Gestão, Educação e Tecnologia Ambiental

REGET/UFSM (e-ISSN: 2236-1170)

\begin{tabular}{|l|l|}
\hline RESÍDUOS & CARACTERÍSTICAS \\
\hline $\begin{array}{l}\text { Resíduos classe I: } \\
\text { perigosos }\end{array}$ & $\begin{array}{l}\text { São classificados como resíduos classe I ou perigosos os resíduos sólidos ou mistura de } \\
\text { resíduos que, em função de suas características de inflamabilidade, corrosividade, } \\
\text { reatividade, toxicidade e patogenicidade, podem apresentar risco à saúde pública, } \\
\text { provocando ou contribuindo para um aumento de mortalidade ou incidência de doenças } \\
\text { e/ou apresentar efeitos adversos ao meio ambiente, quando manuseados ou dispostos de } \\
\text { forma inadequada. }\end{array}$ \\
\hline $\begin{array}{l}\text { Resíduos classe II:não } \\
\text { inertes }\end{array}$ & $\begin{array}{l}\text { Resíduos Classe II Não Inertes: São classificados como Classe II ou resíduos não inertes os } \\
\text { resíduos sólidos ou mistura de resíduos sólidos que não se enquadram na Classe I ou na } \\
\text { Classe II - B. Esses resíduos podem ter propriedades como combustibilidade, } \\
\text { biodegradabilidade ou solubilidade em água. São, basicamente, os resíduos com as } \\
\text { características do lixo doméstico. }\end{array}$ \\
\hline Resíduos \\
inertes
\end{tabular}

Quadro 1 - Classificação dos resíduos e suas características.

Fonte: LIMA (2008)

A Agenda 21 Brasileira, capítulo 21, item 21.3, define os resíduos sólidos “(...) todos os restos domésticos e resíduos não perigosos, tais como os resíduos comerciais e institucionais, os resíduos sólidos da rua e os entulhos de construção".

Na lei dos resíduos sólidos urbanos há uma peça-chave, ou seja, o trabalho dos catadores, considerada essencial para o fim dos lixões e a implantação da coleta seletiva nos diversos municípios no Brasil, com menos poluição e mais renda. As cooperativas são aliadas das empresas nas ações para a reciclagem reforçando o aspecto social. A lei que ampara os catadores prioriza a participação desses a partir da responsabilidade compartilhada entre governo, empresas e a população. O Decreto Federal no 7.404/2010 define a implementação da legislação, prevendo parcerias, incentivos financeiros, capacitação e a melhoria da produção e das condições de trabalho das cooperativas de catadores (CEMPRE, 2010).

Segundo os dados CEMPRE (2010) a distribuição dos municípios com coleta seletiva por regiões é assim constituída: Norte 1\% (05); Centro-Oeste 3\% (13); Nordeste 10\% (45); Sul 36\% (159); Sudeste $50 \%$ (221). Do total de municípios brasileiros, apenas $8 \%$ operam programas de coleta seletiva (CEMPRE, 2010).

Os agentes executores da Coleta Seletiva municipal estão organizados no Brasil, segundo CEMPRE (2010) da seguinte forma: $52 \%$ realizada pelas prefeituras municipais, $26 \%$ empresas particulares e $62 \%$ por cooperativas organizadas pelos catadores.

Nos Estados Unidos, a indústria de reciclagem do lixo tem faturado em torno de 120 bilhões de dólares anual. É um resultado equivalente ao das montadoras de carros americanas, mas com margens de lucro maiores. No Brasil os números são modestos. O economista Calderoni (1997) tem feito a conta no livro "Os Bilhões Perdidos no Lixo" e tem mostrado que o país fatura em torno de 1,2 bilhões de dólares anual com essa atividade. No Brasil, segundo Calderoni (1997) 
HEMPE \& NOGUERA, v(5), n5, p. 682 - 695, 2012.

menos de $1 \%$ do lixo é reciclado e isso significa que é mais fácil um camelo passar pelo buraco de uma agulha do que encontrar uma casa com cinco lixeiras diferentes, uma para cada tipo de detrito. Ao considerar que o Brasil tem 7 milhões de linhas de celular e que $70 \%$ do lixo brasileiro é jogado a céu aberto, a contaminação dos lençóis freáticos localizados abaixo desses lixões não pára de crescer. Quase $70 \%$ é coletado é jogado a céu aberto. Dar destino de forma correta ao lixo é um dos grandes desafios da administração pública em todo o mundo. É calculado que $30 \%$ do lixo brasileiro fica espalhado pelas ruas das grandes cidades. Basta um passeio pelo centro de qualquer capital para perceber o grande número de sacos plásticos, papéis e todo tipo de sujeira pelo chão. O brasileiro não joga o lixo no lixo.

Como pode ser observado na figura 1 , apenas $12 \%$ da população é atendida no Brasil pela coleta seletiva.

Figura 1- População Brasileira atendida pela Coleta Seletiva- 2010

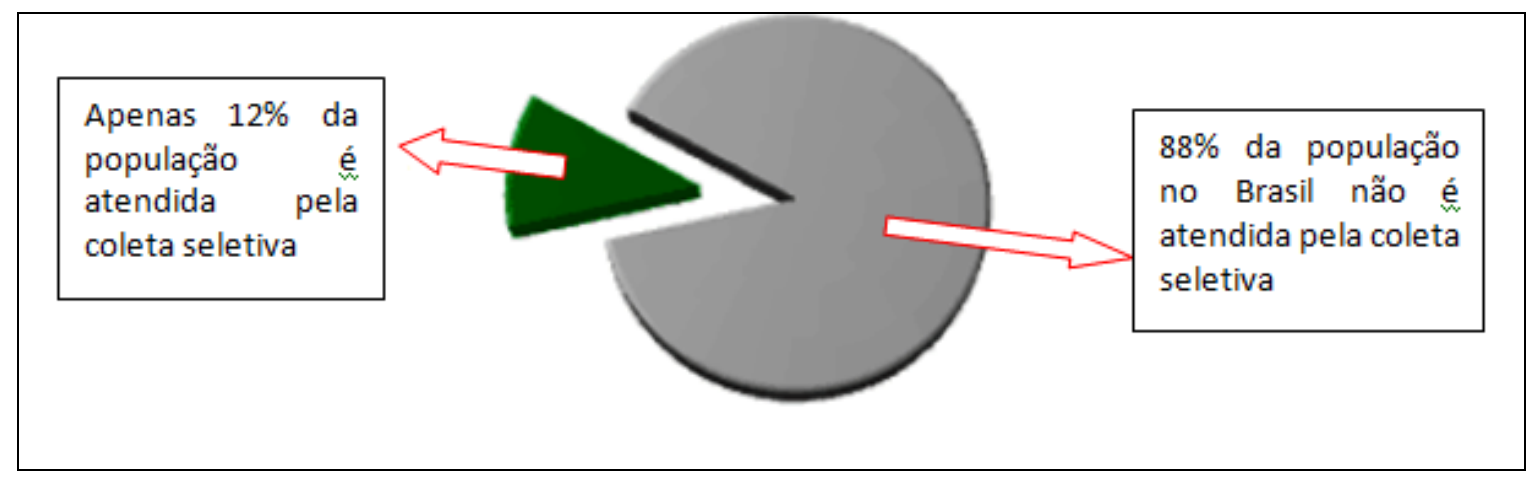

Fonte: CEMPRE, 2010

Durante a oficina de reciclagem que foi apresentada no II Congresso Internacional de Educação Ambiental houve uma breve explanação sobre as diferentes legislações existentes a nível estadual, federal e do município de Panambi-RS, que se refere aos resíduos sólidos e a educação ambiental.

O quadro 2 apresenta algumas das leis que tratam da temática ambiental no município de Panambi-RS.

\begin{tabular}{|l|l|}
\hline \multicolumn{2}{|l|}{ LEGISLAÇÃO MUNICIPAL } \\
\hline $\begin{array}{l}\text { Lei Municipal no } \\
1.357 / 93 \text { de } 31.12 .1993\end{array}$ & $\begin{array}{l}\text { Cria o Conselho Municipal do Meio Ambiente de Panambi - CMA, e dá outras } \\
\text { providências. }\end{array}$ \\
\hline $\begin{array}{l}\text { Lei complementar } \\
\text { municipal no 06/93 de } \\
23.12 .1993\end{array}$ & $\begin{array}{l}\text { Institui o código do meio ambiente e de posturas do município de Panambi/RS e dá } \\
\text { outras providências }\end{array}$ \\
\hline $\begin{array}{l}\text { Lei 2.614 de julho de } \\
2007\end{array}$ & $\begin{array}{l}\text { Dispõe sobre as sacolas plásticas utilizadas pelos estabelecimentos comerciais no } \\
\text { âmbito do município de Panambi/RS. }\end{array}$ \\
\hline
\end{tabular}

Quadro 2 - Legislação: municipal

Fonte: PANAMBI-RS, PREFEITURA MUNICIPAL 
HEMPE \& NOGUERA, v(5), n5, p. 682 - 695, 2012.

Na França, o consumidor tem adotado um novo conceito na hora de comprar, isto é, a possibilidade de reutilização das embalagens. Os empresários têm produzido embalagens retornáveis que são procuradas pelo consumidor graças aos descontos: é o chamado selo verde. Os franceses têm percebido que não se acaba com o lixo atirando-o na lata. O problema começa ali.

Para Ramos (2010) o gerenciamento adequado dos resíduos sólidos urbanos é responsabilidade do poder público e tem sido enfrentado pelos gestores públicos em geral. Toneladas de resíduos são dispostos diariamente em aterros sanitários e lixões, o que podem gerar impactos negativos ao meio ambiente. Para evitar esses danos, o tratamento adequado deve ser dado ao lixo, a fim de evitar que esses resíduos afetem todos os setores da economia e todos os cidadãos residentes próximo a esses locais.

\subsection{Formas de disposição adotadas para os resíduos sólidos urbanos no Brasil}

É possível identificar três formas de destinação final dos resíduos sólidos no Brasil: Lixão, Aterro Controlado e Aterro Sanitário.

Conforme o Manual de Gerenciamento Integrado, IPT/2000, lixão é uma forma inadequada de disposição final dos resíduos sólidos, caracterizada pela descarga, em determinadas áreas, sem medidas de proteção ao meio ambiente e proteção a saúde pública. Localizado em áreas sem preparação anterior e nenhum tratamento de afluentes líquidos. $A$ ausência de controle nestas áreas favorece a proliferação de moscas, aves necrófagas como urubus, haspias e alguns tipos de gavião, além de ratos e outros pequenos animais, que se transformam em vetores de agentes patogênicos. $O$ dano ambiental nestas áreas está associado à presença de catadores de lixo, em busca de materiais recicláveis com aproveitamento econômico. Os lixões têm apresentado grande impacto sobre a paisagem e sua presença causa desconforto e tem trazido a desvalorização das áreas adjacentes.

O aterro controlado é uma forma de disposição criada com vistas à diminuição dos efeitos adversos do lançamento do lixo a céu aberto. Instalação destinada à disposição de resíduos sólidos urbanos cuja técnica consiste em confinar adequadamente os resíduos sólidos urbanos sem poluir o ambiente externo, porém, sem a promoção da coleta e o tratamento dos efluentes líquidos e gasosos produzidos. Normalmente, é descrito como uma célula de um lixão no qual se adotaram tentativas de remediação. Esta célula é preparada para receber os resíduos com sistema de impermeabilização adequada e é operada de forma a reduzir os impactos negativos, com a adoção de providências com a cobertura diária da pilha de lixo com terra ou outro material disponível como forração entre o lixão e o aterro sanitário (Manual de Gerenciamento Integrado, IPT/2000).

A primeira etapa de um projeto de aterro sanitário é a escolha de uma área para implantação e operação do mesmo. O desempenho de um aterro sanitário depende da seleção dos aspectos ambientais, técnicos, econômicos, sociais e de saúde pública. A seleção de áreas para implantação de aterros sanitários é uma das principais dificuldades enfrentadas pelos municípios, principalmente porque uma área, para ser considerada adequada, deve reunir um grande conjunto de condições técnicas, econômicas e ambientais, que demandam o conhecimento de um grande volume de dados e informações, normalmente indisponíveis para as administrações municipais. 
HEMPE \& NOGUERA, v(5), n5, p. 682 - 695, 2012.

Segundo a NBR 13896 (ABNT, 1997), a avaliação da adequabilidade de um local a ser utilizado para implantação de um aterro sanitário deve levar em conta os impactos ambientais gerados na sua implantação e operação sejam mínimos. A instalação deve ser aceita pela população vizinha; é necessário estar de acordo com o zoneamento local e que possa ser utilizado por longo período de tempo. Para ser ter uma estimativa do tamanho da área, e mesmo para auxiliar as etapas seguintes, é necessário estimar a geração de resíduos e o volume do aterro. A estimativa atual de geração de resíduos sólidos municipais pode ser feita aplicando uma fórmula (LIMA, 2008).

2.5 A educação ambiental, as tecnologias e a função dos professores neste século XXI.

A primeira década do século XXI é caracterizada pela presença maciça de tecnologias na vida das pessoas. Neste sentido, citam-se jogos interativos, redes sociais, objetos virtuais de aprendizagem, entre outros. Esta realidade favorece o trabalho do professor que pode e deve utilizar-se destes recursos para trabalhar, por exemplo, com a temática ambiental. Desta forma, além de ensinar, oportuniza a aprendizagem de forma prazerosa.

Segundo Piaget (1993) a aprendizagem com crianças deve contemplar a brincadeira, e o jogo é um tipo de atividade poderosa para o exercício da vida social e da atividade construtiva da criança. Para Balestro (2004) apud (Filho (SD) o jogo possui duas funções educativas: uma função lúdica, na qual a criança encontra prazer ao jogar, e uma função educativa, que consiste em desenvolver o conhecimento da criança e sua apreensão do mundo.

Segundo Filho (S.D, p.1) "a escola é considerada um elemento de transformação da sociedade, e uma de suas funções é contribuir, junto com outras instâncias da vida social, para que essas transformações se efetivem".

Diferentes trabalhos acadêmicos como monografias, dissertações, teses, entre outros, destacam a temática de inserção tecnológica no processo ensino-aprendizagem. Um exemplo prático foi descrito por Tuzzin (2010, p.11) referindo-se ao uso de objetos virtuais de aprendizagem para potencializar competências leitoras "[...] o uso deste objeto de aprendizagem fomenta o aperfeiçoamento de competências ligadas aos domínios de estratégias de leitura [...]" desta fala, é possível inferir que o uso de tecnologias na sala de aula, além de acentuar o aspecto lúdico, no trabalho escolar, defendido por Piaget (1993) e por Balestro (2004), aperfeiçoa a leitura dos estudantes. Tuzzin $(2010$, p.) em seu estudo reforça seu posicionamento pelo uso de tecnologias no cotidiano escolar ao afirmar [...] acredita-se que ao utilizar, reflexivamente, objetos de aprendizagem no ensino da leitura e da escrita desenvolvem-se competências que poderão ser constatadas na edição da avaliação externa [...] .

A educação ambiental deve estar presente no cotidiano escolar, em todas as escolas e em todas as classes, séries e ou ano.

Segundo Reigota (1994),

... é consenso entre a comunidade internacional que Educação Ambiental deve estar presente em todos os espaços que dotam os cidadãos de aprendizado - formal, não formal ou informal. Neste contexto, a escola, como responsável pela formação integral de cidadãos tem o dever social de desenvolver sistemas de conhecimentos, preceitos e valores que construam a conduta e fundamentem o comportamento próprio de proteção do meio ambiente. Na comunidade escolar a reflexão compartilhada, conjugada, traceja e esclarece o papel de cada ator social nos trabalhos com o meio ambiente. A escola é de longe, o ambiente ideal para se trabalhar conteúdos e metodologias adequadas a esses 
HEMPE \& NOGUERA, v(5), n5, p. 682 - 695, 2012.

Revista Eletrônica em Gestão, Educação e Tecnologia Ambiental

REGET/UFSM (e-ISSN: 2236-1170)

propósitos. Com obviedade, a escola e a Educação Ambiental - isoladamente, não trarão soluções para a complexidade que se revestem os problemas socioambientais do planeta, entretanto, o convívio escolar exerce, decididamente, influência nas práticas cognitivas, bem como na formação de um novo sujeito social: redefinindo a relação das pessoas na conjuntura cultural/ambiental, se traduzindo no ponto de equilíbrio, de interligação na busca do convívio coesivo entre o homem e o meio ambiente, redimensionando o comportamento humano em relação ao planeta - nas formas local e global.

A educação ambiental propõe neste século um novo conceito educacional, isto é, propõe que a escola enseje ações com relação ao meio ambiente de forma individual e de forma coletiva redimensionando a relação entre os atores sociais envolvidos na comunidade escolar (pais, docentes, discentes, secretários, etc.), enfatizando - fundamentalmente o papel do professor, que não obstante seja de coadjuvante neste inusitado conceito de escola/ensino/aprendizagem para a formação do novo ser socioambiental para o século XXI (FREIRE, 1997).O educador democrático deve reforçar a capacidade crítica do educando, sua curiosidade, sua submissão.

O educador tem um importante papel, ensinar o que é certo. Segundo Flick (2011) na nova ordem mundial faz-se mister uma formação para os profissionais de educação cujos ensinamentos e práticas pedagógicas estejam voltados para os novos paradigmas da educação. Estes novos paradigmas exigem conhecimentos metodológicos específicos, bem como novas relações com os conteúdos holísticos.

A seguir apresentam-se sugestões de jogos interativos para trabalhar a educação ambiental de forma lúdica e prazerosos.

\begin{tabular}{|c|c|}
\hline ENDEREÇO ELETRÔNICO E & DICAS PARA O PROFESSOR \\
\hline $\begin{array}{l}\text { http://www.escolagames.com.br/jogo } \\
\text { s/coletaSeletiva/ }\end{array}$ & $\begin{array}{l}\text { De uma maneira divertida, o jogo contribui como desenvolvimento da } \\
\text { consciência ecológica da criança, pois ela memoriza rapidamente as } \\
\text { cores usadas na Coleta Seletiva e aprende como separar os resíduos } \\
\text { para a reciclagem. Além disso, a cada avanço, ela recebe informações } \\
\text { de fácil entendimento sobre os danos que esses resíduos causam à } \\
\text { natureza, caso não sejam reciclados. }\end{array}$ \\
\hline $\begin{array}{l}\text { http://www.foxjogos.com/jogos- } \\
\text { online/recycle }\end{array}$ & $\begin{array}{l}\text { Recicle a maior quantidade de lixo no tempo de } 1 \text { minuto. A cada acerto } \\
\text { que você fizer irá somar } 5 \text { pontos. Mostre que você é fera em } \\
\text { reciclagem. }\end{array}$ \\
\hline $\begin{array}{l}\text { http://www2.uol.com.br/ecokids/jogo } \\
\text { s/arca_01.htm }\end{array}$ & Ajude a deixar o meio ambiente limpo. \\
\hline $\begin{array}{l}\text { http://iguinho.ig.com.br/jogo_reciclag } \\
\text { em.html }\end{array}$ & Ajude a classificar e colocar o lixo nas lixeiras corretas \\
\hline $\begin{array}{l}\text { http://www.iguinho.com.br/teste- } \\
\text { natureza.html }\end{array}$ & Questões sobre o meio ambiente. \\
\hline $\begin{array}{l}\text { http://www.elfland.com.br/jogos/tart } \\
\text { arugas/index.html }\end{array}$ & Ajude as tartarugas a livrar-se dos pneus e litros jogados na praia \\
\hline
\end{tabular}


HEMPE \& NOGUERA, v(5), n5, p. 682 - 695, 2012.

Revista Eletrônica em Gestão, Educação e Tecnologia Ambiental

REGET/UFSM (e-ISSN: 2236-1170)

Quadro 2 - Jogos interativos disponíveis na Internet

Elaboração: Autores

Durante a realização da oficina de reciclagem para os alunos da educação básica realizada no II Congresso Internacional de Educação Ambiental e VI Seminário Municipal do Meio Ambiente foram disponibilizados os endereços eletrônicos dos jogos conforme descrições no quadro 2: jogos interativos.

Concordo com Flick (2010) quando diz que o "educador, enquanto profissional da educação, no exercício da sua função tem um grande desafio para o Século XXI: a formação da consciência ambiental dos alunos e o desenvolvimento e exercício da sua cidadania (...)" e também fazer o uso das tecnologias na sala de aula.

Existem inúmeros artigos, sites e informações sobre as questões ambientais, cabe ao professor buscar e trabalhar com seus discentes, procurando desenvolver nestes a consciência ambiental de forma holística.

\section{METODOLOGIA}

Para a elaboração da pesquisa foram rastreados na internet artigos científicos, vídeos do you tube e jogos online de educação ambiental. Após foram selecionados de acordo com a temática que havia sido escolhido. As atividades oferecidas na oficina constaram de parte explicativa oral, vídeos e jogos. A apresentação oral foi apresentada através de power point, o qual foi organizado a partir do referencial teórico elaborado. Apresentaram-se dois vídeos. Um dos vídeos foi para sensibilizar sobre os problemas ambientais do Planeta, o qual foi selecionado na internet. O segundo vídeo foi sobre a usina de triagem de resíduos sólidos, o qual foi organizado/elaborado pela autora do artigo. Utilizou-se para elaborar o segundo vídeo software movi maker e fotos da época da inauguração da referida usina.

As atividades tiveram o intuito de sensibilizar os participantes sobre as questões ambientais e também mostrar aos professores presentes na oficina de reciclagem que as tecnologias chegaram e que não te volta. Só haverá mudança no processo de ensino/aprendizagem quando o professor conseguir incluir dentro de uma visão integral todas as tecnologias: as telemáticas, as audiovisuais, as textuais, as orais, as musicais, as lúdicas e as corporais (MORAN, 2000 apud HEMPE, 2010). Na internet existem muitos vídeos do you Tube, artigos científicos que podem ser utilizados para embasamento teórico dos professores para trabalhar as questões ambientais. Para trabalhar educação ambiental o professor pode buscar sua própria capacitação e ou aperfeiçoamento.

\section{RESULTADOS E ANÁLISES}

O presente trabalho de pesquisa fez parte da programação do II Congresso Internacional de Educação Ambiental e VI Seminário Municipal do Meio Ambiente que se realizou em PanambiRS, nos dias 23, 24 e 25 de setembro de 2011, conforme figura 2 - Momento da explanação sobre as etapas da oficina.

Primeiramente foi apresentado um vídeo intitulado "Reciclagem", cujo autor é Fernando Leal e Guilherme Leão. No segundo momento houve explanação oral sobre os conceitos de educação ambiental, as leis que existem nas três esferas, as formas de disposição do recolhimento de resíduos sólidos no Brasil, e em Panambi-RS. Num terceiro momento apresentou-se 
HEMPE \& NOGUERA, v(5), n5, p. 682 - 695, 2012.

novamente um vídeo mostrando as instalações da Usina de Triagem de Resíduos Sólidos de Panambi-RS, no inicio da sua instalação. E como última atividade foi acessado o jogo interativo online disponível no endereço eletônico: <http://www.escolagames.com.br/jogos/coletaSeletiva/>. Participaram da oficina de reciclagem em torno de cento e vinte alunos da Educação Básica de Panambi-RS.

Os professores T. N. e J. O. C. N. (professores da UFSM) também assistiram a participaram da oficina. Estes colaboraram e auxiliaram os alunos no momento de colocar os resíduos/lixos nos devidos contêineres, de forma online. Estes instigaram com os alunos sobre a diferença entre o resíduo e lixo. Dialogaram com os participantes, perguntando em que contêineres seriam colocados os diferentes tipos de lixos. A figura 3 - mostra os momentos finais da oficina onde os alunos tiveram a oportunidade de jogar de forma online.

Os alunos conversavam entre si e respondiam, após refletirem sobre qual resposta seria a correta (...). Foram disponibilizados os endereços eletrônicos dos demais jogos do quadro 2, para que os participantes da oficina pudessem acessar na escola, em suas casas, etc. Os jogos oportunizam aprendizagem de forma lúdica e prazerosa.

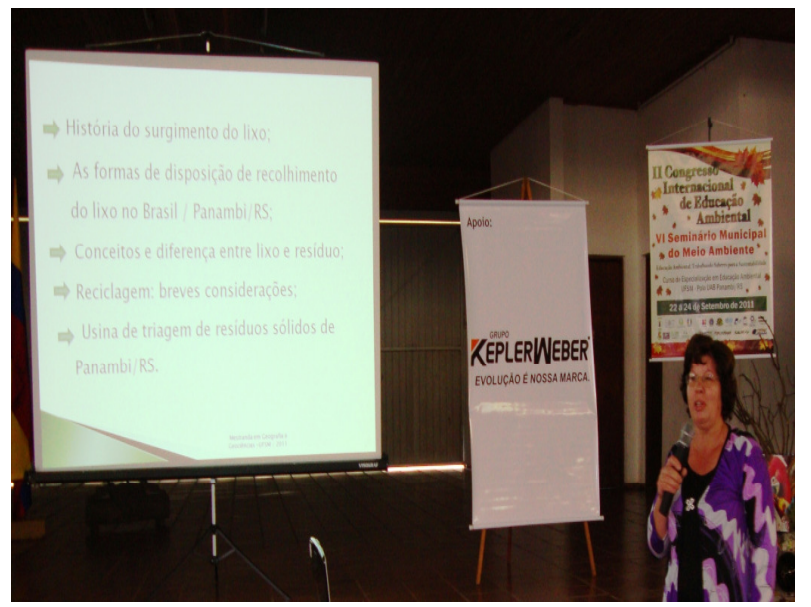

Figura 2-Momento inicial da explanação sobre as etapas da oficina de reciclagem: a educação ambiental e os resíduos sólidos.

Fonte: Autores

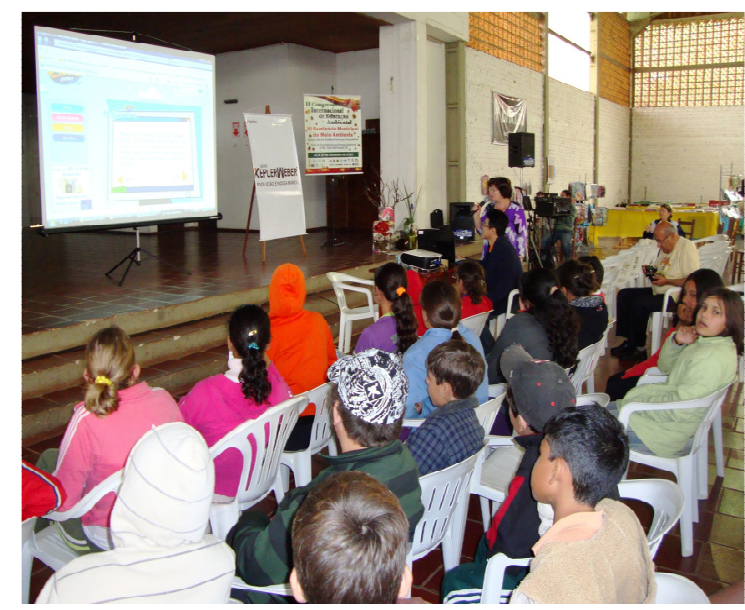

Figura 3-Momento final da oficina de reciclagem: educação ambiental e os resíduos sólidos. Fonte: Autores

\section{CONCLUSÃO}

O público presente na "Oficina de reciclagem: educação ambiental e os resíduos sólidos" demonstrou interesse, após a apresentação vários professores procuraram para saber mais informações sobre o acesso aos jogos interativos. Os alunos participaram ativamente de todos os momentos do jogo online e das diversas explicações.

Os conceitos pesquisados e apresentados dos diversos autores dos artigos diferem na sua interpretação. Cada autor enfatiza a legislação a sua maneira. Apesar de a legislação nacional, estadual e municipal possuir dispositivos explícitos que possibilitam a conservação e a preservação 
HEMPE \& NOGUERA, v(5), n5, p. 682 - 695, 2012.

do meio ambiente, ainda existem municípios cujos gestores são penalizados por não colocarem em prática o previsto na legislação do próprio município.

A legislação sobre a temática resíduos sólidos é vasta por isso alguns recortes foram feitos para fins desta oficina. As formas de destinação final dos resíduos sólidos no Brasil totalizam três, são eles: Lixão, Aterro Controlado e Aterro Sanitário.

No caso do município de Panambi-RS já evoluiu, pois na década de 60 havia um lixão a céu aberto, na década de 70 teve inicio o processo de tratamento do lixo, na ocasião o local de depósito foi denominado de Unidade de Tratamento do Lixo de Panambi, com localização na BR 158, o qual permaneceu até o ano de 2001. Em março de 2001 foi inaugurada a nova usina de Triagem de Resíduos Sólidos Urbanos, localizada na Linha Rincão Frente- Zona Rural. Os participantes da oficina tiveram a oportunizada de assistir um vídeo onde mostra todas as dependências da usina na época de sua inauguração.

É importante que o gestor municipal, juntamente com as demais secretarias elaborem projetos com ações integradas e envolvimento de todos, para que as temáticas "educação ambiental e resíduos sólidos" sejam abordadas durante o ano todo, e os colaboradores se tornem disseminadores de práticas ambientais. Neste sentido há uma grande caminhada a ser percorrida para que a coleta seletiva de lixo chegue todos os recantos desde Brasil afora.

\section{REFERÊNCIAS}

ASSOCIAÇÃO BRASILEIRA DE NORMAS TÉCNICAS. 2004. Resíduos sólidos - classificação: NBR-10004. Rio de Janeiro: ABNT 63p.

AMORIM, A.P. et al. Lixão municipal: abordagem de uma problemática ambiental na cidade de Rio Grande - RS. Disponível em: http://www.seer.furg.br/ojs/index.php/ambeduc/article/viewFile/888/920>. Acesso em 24 de maio de 2011.

CALDEROINI, Sabetai. Os bilhões perdidos no lixo. São Paulo; Ed. Humanistas, 1997.

BRASIL. Senado Federal. Agenda 21 Conferência das Nações Unidas sobre o meio ambiente e desenvolvimento. 3 ed. Brasília: Senado Federal, subsecretaria de edições, 2001.

CEMPRE. Lixo Municipal: manual de gerenciamento integrado. São Paulo: IPT/ CEMPRE , 2000. 370p.

Decreto no 38.356, de 1ำ de abril de1998. Gestão dos resíduos sólidos no Rio Grande do Sul.

Decreto no 7.404 de 23 de dezembro de 2010. Trata sobre Dispensa de Licitação para contratação de Catadores de Resíduos.

GUANABARA, R., GAMA, T.,EIGENHEER,E,M. Os resíduos sólidos como tema gerador: da pedagogia dos três R's ao risco ambiental. Revista eletrônica do Mestrado em Educação Ambiental .v.21, jul a dez de 2008.

FILHO, José Walter Santos Filho. Jogo tartarugas: Objeto de Aprendizagem na Educação Ambiental. HEMPE, Cléa. Midias no contexto escolar: investigação sobre o uso das mídias na sala de aula presencial. Artigo apresentado no Curso Especialização em Mídias na Educação. Dez/2010. UFSM.

YOSHITAKE, m. Teoria do Controle Gerencial. São Paulo: Ibradem, 2004. 
HEMPE \& NOGUERA, v(5), n5, p. 682 - 695, 2012.

LAYRARQUES. Philips. O Cinismo da Reciclagem: 0 significado da reciclagem e suas implicações para a educação ambiental. In Loreiro F. Layargues, P. Castro (Orgs) Educação Ambiental; repensando o espaço da cidadania. São Paulo; Cortez,2002,.

LIMA, Wesley Schettino de (conteudista); CATAPRETA, Cícero Antônio Antunes (conteudista).Resíduos Sólidos. Guia do Profissional em Treinamento. Nível 2. Rede de Capacitação e Extensão Tecnológica em Saneamento Ambiente / Secretaria Nacional de Saneamento Ambiental (org.). - Belo Horizonte ,- ReCESA , 2008.

MELO, F. R. Q., KORF.E. P. Percepção e sensibilização ambiental de universitários sobre os impactos ambientais da disposição de resíduos sólidos urbanos em Passo Fundo - RS. Revista Brasileira de Educação Ambiental.

MINISTERIO DO MEIO AMBIENTE. Legislação. http://www.mma.gov.br/sitio/index.php?ido=legislacao.index\&tipo=0>. Acesso em: 12 de jul 2011.

MOURA, A. C. M. Reflexões Metodológicas como subsídio para Estudos Ambientais Baseados em Análise de Multicritérios. In Anais XIII Simpósio Brasileiro de Sensoriamento Remoto. Florianópolis, Brasil, 21-26 abril, 2007.

NOGUERA, Jorge Orlando Cuellar (professor Conteudista- UFSM). Curso de Especialização em Educação Ambiental. Disciplina Abordagem das Questões Ambientais: Poluição Urbana, Ar e Resíduos Sólidos e Urbanos (2010). Xerox materiais do Curso. Polo de Apoio Presencial - Panambi - RS.

PIAGET, J. A linguagem e o pensamento da criança.6ạ edição.São Paulo:Martins Fontes,1993.

RIZZO, Marçal. Rogério. O Consumismo, o Meio Ambiente e a Violência, 2008.

RAMOS, J. S. Gestão integrada de resíduos sólidos em instituições de ensino: estudo de caso para aplicação nas Faculdades Kennedy. Revistos resíduos em referência - Gestão de Resíduos e Sustentabilidade. Dez 2010.

REIGOTA, Marcos. O que é educação ambiental. São Paulo: Brasiliense, 2006.

RIO GRANDE DO SUL. (ESTADO), 1993. Lei no 9.921, de 27 de julho de 1993. Dispõe da Gestão dos Resíduos Sólidos no Estado. Porto Alegre, RS: Gabinete do Governador do Estado do Rio Grande do Sul, Antonio Britto.

RIO GRANDE DO SUL.(ESTADO), 1998. Decreto no 38.356, de 1 de abril de 1998. Aprova o regulamento da Lei de 27 de julho de 1993 que dispõe sobre a Gestão dos Resíduos sólidos no Rio Grande do Sul. Diário Oficial do Estado, Porto Alegre, RS.

SCHEREN, M. A. A educação ambiental e a gestão integrada do tratamento e destino final dos resíduos sólidos no Município de Sede Nova/RS. Disponível em: http://www.remea.furg.br/edicoes/vol13/art10v13.PDF> Acesso em 24 de maio de 2011.

TUZZIN, Maria Cardoso. Utilização de objeto de aprendizagem. Relato de experiência de ensino de leitura e escrita. Dissertação do Curso de Especialização em Tecnologia da Informação e Comunicação Aplicada a educação, Polo de Três de Maio, 2010.Disponível em: <http://www.slideshare.net/CursoTICs/maria-iraci-cardoso-tuzzin>. Acesso em 18 de set 2011 . 